\title{
Article \\ From Ecophany to Burnout? An Anthropologist's Reflections on Two Years of Participating in Council-Citizen Climate Governance in Eastbourne
}

\author{
Pauline von Hellermann
}

Department of Anthropology, Goldsmiths University, London SE14 6NW, UK; p.vonhellermann@gold.ac.uk

\begin{abstract}
In July 2019, Eastbourne Borough Council declared a climate emergency and committed to making Eastbourne carbon neutral by 2030. In order to achieve this, citizens together with Council created a unique model of council-citizen collaborative climate governance, the Eastbourne Eco Action Network (EAN). EAN's main strategy has been the setting up of targeted working groups, each bringing together Councillors, engaged citizens and providers, and each tackling a specific area of climate action through a combination of infrastructure, institutional and behavioural changes. As an environmental anthropologist living in Eastbourne, I was involved in this process right from the beginning, having had my own 'ecophany' — the realisation that the climate emergency required urgent action-in February 2019. Two years and one pandemic later, in this paper I reflect on the overall experiences and challenges of EAN's and Eastbourne Borough Council's work towards townwide carbon neutrality to date, discussing possible factors (structural and other) determining varying successes and failures. At the same time, this paper provides an auto-ethnographic account of what 'engaged anthropology' means in practice, mapping out the real contributions anthropologists can and should make in local climate action, but also reflecting on challenges encountered along the way.
\end{abstract}

Keywords: council-citizen collaboration; climate action; activist anthropology; volunteering; carbon neutral; targets; labour; pragmatism

\section{Introduction}

On 10 July 2019, Eastbourne Borough Council declared a climate emergency, one of dozens of UK councils to do so that summer. For Eastbourne-a provincial, conservative seaside town in East Sussex, largely known as a retirement place and coach holiday destination - this declaration, and a concomitant commitment to make Eastbourne Carbon Neutral by 2030, were quite remarkable. Both were ensured and supported by a majority of (Liberal Democrat and Conservative) Eastbourne Councillors, but also the results of vociferous campaigning by local environmental groups. Eastbourne's Friends of the Earth long-standing efforts gained considerable momentum from early 2019, when, spurred on by Greta Thunberg and the Fridays for Future and Youth Climate movement, a number of new eco groups and activists sprung up in Eastbourne: Extinction Rebellion, Youth Climate Strikes and the group I had set up, Parents for Future. Led by Henry (all names of Eastbourne residents mentioned in this paper are pseudonyms), the chair of Eastbourne Friends of the Earth, these groups started networking and thinking about closer collaboration with each other and with Council. We held a first 'café' style meeting in June, which Councillors were also invited to, at which we first brainstormed different ideas of what could and should be done locally to address climate change. It was as a result of this meeting, and ongoing conversations, that, on 11th July, the day after the Climate Emergency Declaration, Eastbourne Borough Council invited a number of us to a meeting in the Town Hall, and we decided together to set up the Eastbourne Eco Action Network (EAN), as a citizen-based group working together with Council to achieve the Eastbourne Carbon Neutral 2030 goal. 
Two years and one (ongoing) pandemic later, this paper takes stock of our efforts to date. It describes how we designed this particular council-citizen collaboration, the ideas and thinking going into this, and how we have fared since, pandemic and all. I look at the organisation as a whole but also different groups and projects (within the EAN network but also outside it) comparatively, analysing different structural, politicoeconomic and 'personality' factors that contributed to particular 'successes' and 'failures'. The second part of the paper is about my own experiences and reflections during this involvement. These are both about the personal—and in particular the immense burden of taking up such a project, leading to near burnout several times-and wider reflections about engaged anthropology.

I continue to believe in and advocate engaged anthropology, despite the high personal costs of engagement. More and more academics [1-3] now argue that we need to rethink the role of academia, and our individual roles as academics, and to start contributing directly to climate action. I would like to add to these powerful calls by emphasising, firstly, the skills all academics can bring to climate action: organising and chairing meetings; email, communication, IT, and administrative skills; public speaking, 'science communication' and writing of funding bids; and, of course, research skills and knowledge-skills we may take for granted but that are actually really valuable for climate action. Secondly, anthropology specifically can offer so much: our understanding of culture and practices can be applied to challenging and changing perception of what is considered 'normal' or 'good', for example about car culture, good parenting, careers; we have so much knowledge of different, diverse ways of living from around the world and throughout history that can help in the search for better ways of living; and we have spent decades studying politics, power and communities, all insights that lend themselves to better climate action. Thirdly, as I explore more in the Unorthodox Methodology section and throughout the paper, this kind of practice-based learning can really enrich traditional research approaches in anthropology.

Overall-because it is still ongoing, because I am so involved, emotionally, practically and intellectually, and because the climate crisis as a whole is overwhelming and we are all still just muddling through — the paper's analysis of what we have achieved here in Eastbourne 'veers' somewhat between different optimistic and pessimistic 'takes'; an accurate reflection of my overall state of mind. However, it does all add up to an emerging overall theory of change, which I end the paper with by way of a conclusion.

\section{Unorthodox Methodology}

This paper marks a departure for me as an anthropologist in research and writing in that it is almost entirely practice-based, auto-ethnographic, and on quite a different topic to my previous and ongoing work e.g., [4-6]. I became involved in climate action in Eastbourne not for research purposes but as a concerned citizen and have been doing this in my 'spare time'-my 'real' current research is on palm oil (I am currently a Leverhulme Major Research Fellow, working on 'Red Gold: A Global Environmental Anthropology of Palm Oil' (2018-2022)). I have therefore not been in the position to conduct much actual research or to familiarise myself with relevant literature on UK local government or climate action. Instead, it draws almost exclusively on my own experiences, observations and analysis as an active core participant. As such, my account cannot claim to be objective: it is situated and subjective, shaped by my own interactions, emotions, and particular trajectory. For example, I have much more frequent contact with some of the people I write about than others, and differently positioned interpersonal and professional relations, and am also, of course, informed by my wider but particular knowledge and outlook as an anthropologist.

I only thought of writing about Eastbourne's climate action when invited to contribute to this Special Issue, more than two years in to my active involvement. I was therefore not able to gain permission and consent at the start of 'research' - most of the events I describe took place before this invitation. However, I discussed writing this paper with key Councillors, Council officers and volunteers and gained their informed consent; as I 
did for the three short interviews I conducted, with Catherine (EBC Sustainability Officer), Carl (Treebourne) and Paul (EAN Transport Group). I should be explicit that I was not able to gain consent from every person mentioned here, mostly again for time reasons, but also because of my particular subjective position and experiences. I have, of course, endeavoured to be fair and generous in my portrayal of all involved, but it is part of the nature of auto-ethnographic writing about my own, active participation that my relations to those around me are very different and more uneven than usual 'researcher-informant' relations, and my account no doubt reflects this.

Although the unorthodox approach to research and writing adopted here was thus initially born out of necessity, it was also a deliberate methodological choice. I chose a largely auto-ethnographic account to present more authentically from the perspective of a participant rather than academic analyst; and I wanted to foreground and explore a different kind of learning and thinking, one deriving primarily from active engagementthe limited amount of 'practical wisdom' [7] I have gained along the way. Indeed, having never done this before, I found this approach extraordinarily rewarding. As a discipline, we anthropologists pride ourselves on 'deep immersion' and participant observation; yet, in practice, as long as research and writing remain our central aim, we are always more observant than participant. As I discovered, it is through real participation and actionwith one's own goals and ambitions as an involved actor-that one learns so much more, and very differently, than during 'fieldwork'. There is also, I discovered, real value in 'dipping into' a different topic and region to your normal work in this way. Although this piece may not be as academically grounded in relevant literature as it could be, I have discovered a few surprising and illuminating synergies and connections between this and other, ongoing research into palm oil and conservation. There is value in sometimes jumping around a little.

\section{Setting Up Eastbourne's Carbon Neutral 2030 Campaign and the Eco Action Network}

The day of 10 July 2019 was sunny and happy for Eastbourne eco activists. A sizeable crowd of us, with families and friends in tow and armed with placards, signs, posters, and a large puppet, gathered on the steps of the Town Hall to greet Councillors, on their way in to a Council Meeting, with our demand to declare a Climate Emergency. Having already met and campaigned together quite a few times over the preceding months-forming new groups, doing a cycle rally, participating in youth climate strikes, our Climate Café event, etc. - we all knew each other by then, and the overall mood and togetherness is captured well in a photograph taken on the day (Figure 1). To the extent that any further pressure was needed (most of the groundwork had been done in previous months; the protest outside was more symbolic, although still important), we succeeded: a climate emergency was indeed declared, and Eastbourne Borough Council (EBC) committed to Eastbourne becoming Carbon Neutral by 2030. Participants in the Council meeting reported that the decision was taken more or less unanimously, with both Conservative and Lib Dem Councillors agreeing. Setting the comparatively ambitious target of carbon neutrality by 2030, applying, importantly, not just to the Council's own carbon footprint but to the town as a whole, felt like a real move in the right direction.

The meeting the next day, with around 25 of us-EBC Councillors and officers, Chamber of Commerce representatives and eco activists-gathered in the Town Hall, was equally important and positive. Councillor Richard told us about the Council's plans to appoint a new Sustainability Officer, and about Council funds available to the Carbon Neutral 2030 campaign-around GBP 10,000 per annum. He emphasised EBC's limited capacities, both in terms of resources and remit: as a two-tier authority, some of the sectors relevant for becoming carbon neutral, such as transport and roads, are under the remit of East Sussex County Council (ESCC), not EBC. We all agreed that EBC needed the support of activist groups, experts and citizens to achieve the Carbon Neutral 2030 target. We also discussed different definitions of this, settling, still somewhat ambiguously, on 'carbon neutrality within town boundaries', and resolved that we would all come together in 
the Eco Action Network (EAN). This network would register as a Community Interest Company (CIC), with activists as directors, so that we could raise funds. Moreover, we decided to form focused working groups, each bringing together Councillors, citizens and 'specialist' (professionals, long-standing experts and those working in existing relevant NGOs or pressure groups). Because I had already for some months been trying to set up a local eco-school network through my small Parents for Future group, we decided that I would lead the education group (Figure 2).

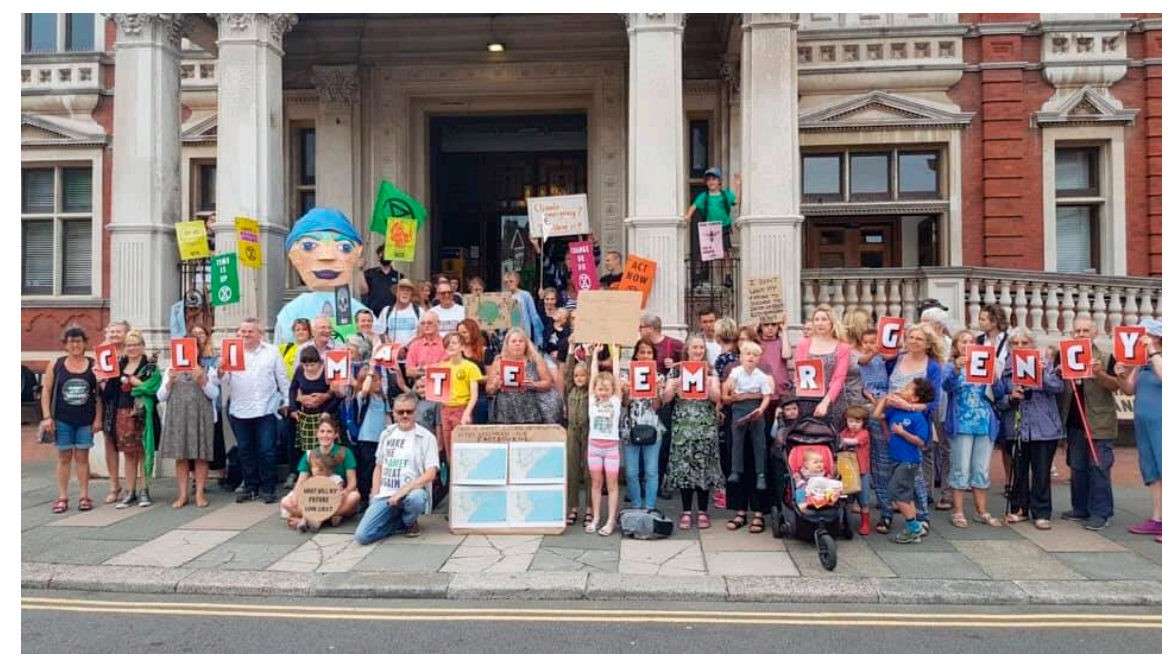

Figure 1. Protest outside Eastbourne Town Hall for Climate Emergency, 10 July 2019 @Courtesy of the Eastbourne Herald.

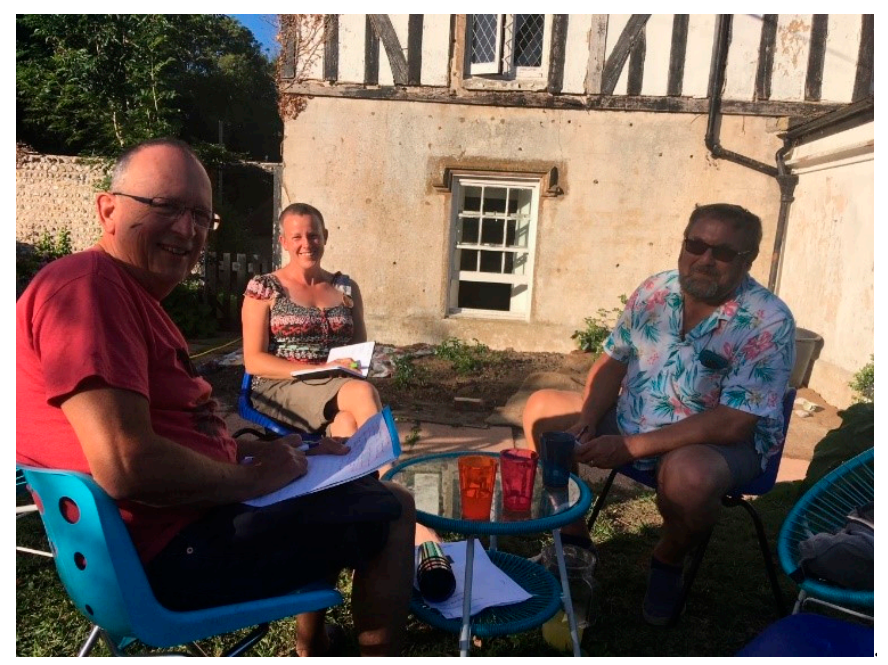

Figure 2. First education group meeting at Langney Priory, 15 July 2019 @ P von Hellermann.

Over the next few months, both the Eco Action Network and the Carbon Neutral 2030 campaign were consolidated and formally launched. On 9 November, we held the official EAN launch meeting, in the conference room of the Town Hall. With over 60 people in attendance, I laid out our overall vision of the EAN, and how we would work together with Eastbourne Borough Council towards our Carbon Neutral 2030 goal through focused working groups (Figures 3 and 4 ). 


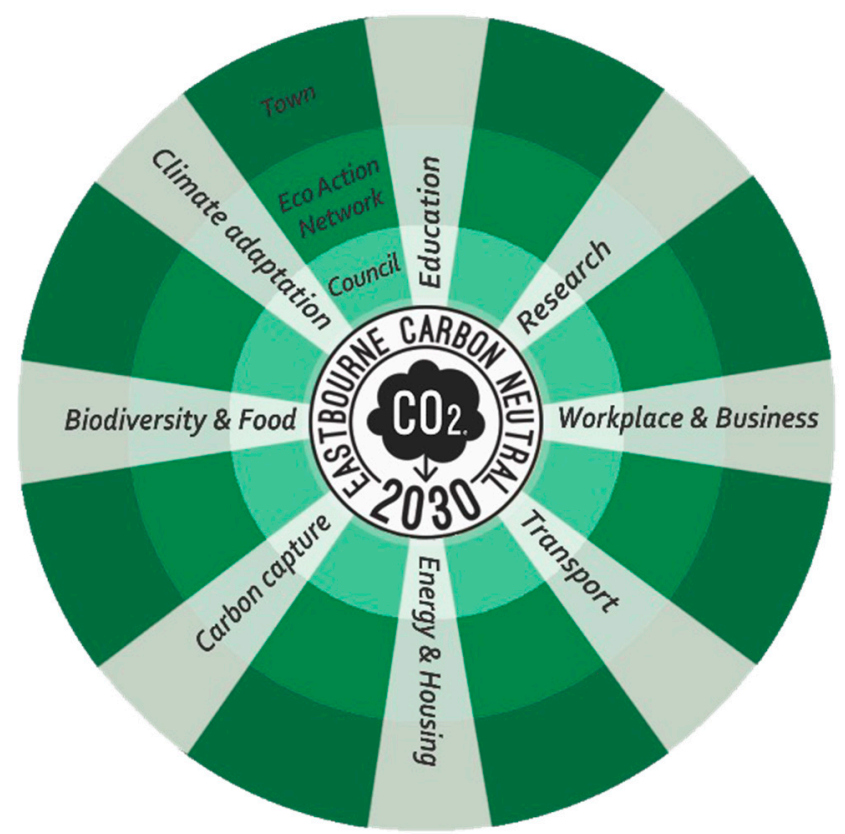

Figure 3. Visualisation of council-citizen collaboration @ P von Hellermann and Roxana Caporici.

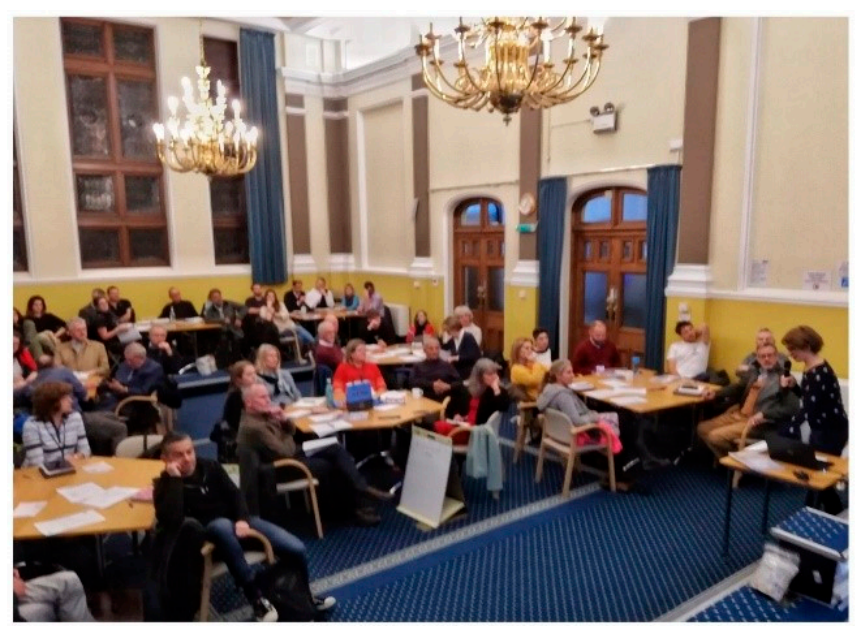

Figure 4. Author on right giving talk at EAN inaugural meeting, 9 November 2019 @Brian Booker.

For the rest of the meeting, people broke up into smaller group discussions, so that each working group could start initial conversations, create a contact list and communication forum, and gather ideas. This, too, was a positive, constructive meeting, in which we felt we had set up the basic structures for feasible, inclusive, egalitarian and flexible council-citizen collaboration. Over the following weeks, the working groups started meeting and working together, whilst the EAN directors focused on creating a website and Trello platform and on working with Eastbourne Borough Council, which was developing its own strategies and creating the Sustainability Officer position.

The next joint step was an Eastbourne-wide, public information event to officially launch Eastbourne's Carbon Neutral 2030 campaign on 18 January 2020. Held in two large halls in the basements of Eastbourne's newly opened (Council-owned) Welcome building, there were 40-50 stalls by a wide range of eco-organisations, including, for example, Lewes' solar panel producer Ovesco, the Eastbourne UN Association and Extinction Rebellion, to name a few. There were talks and performances and a stream of visitors throughout the day, with a footfall of over 3000 people recorded (Figures 5 and 6). 


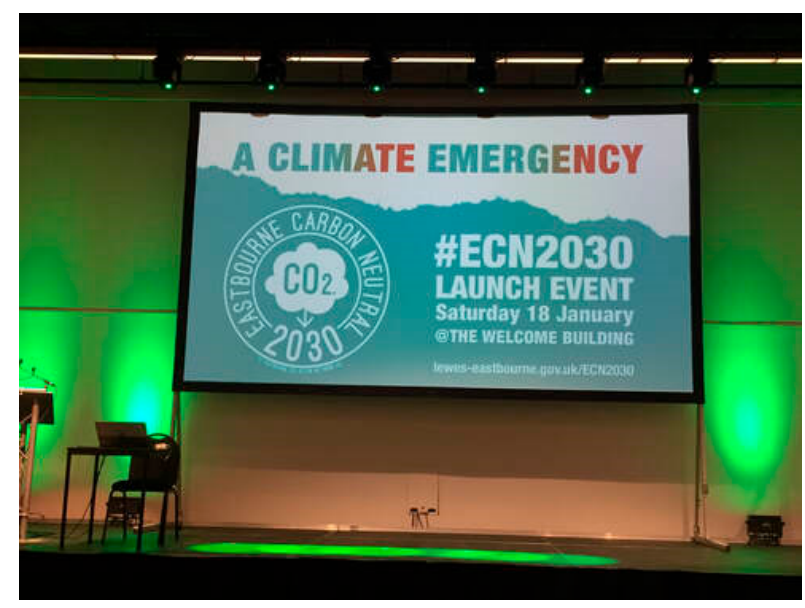

Figure 5. Carbo Neutral 2030 Launch event, Welcome Building, Eastbourne, 18 January 2020 @UNA Eastbourne.

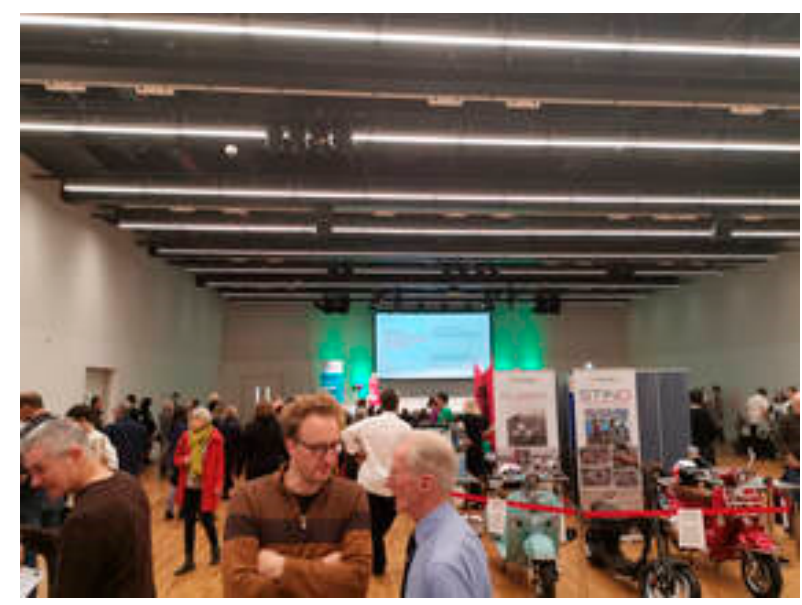

Figure 6. Stalls and visitors at Carbon Neutral 2030 Launch event, 18 January 2020 @UNA Eastbourne.

Again, there was much positive energy, and after the event many more people signed up to join EAN. EBC and EAN collaboration, meanwhile, continued in now routinized and established forms, with both individual Councillors participating in working groups and the EBC Climate Change Strategy Group, which included EAN directors, meeting regularly. Most importantly, the newly appointed Sustainability Officer worked with this committee on putting together an 'ECN2030 Eastbourne Borough Council Climate Emergency Strategy', laying out an action plan [8] for reaching carbon neutrality by 2030. As one of the EAN's core architects, at this point I was proud and excited that we had developed our own, unique form of council-citizen collaboration-in a socially and politically conservative small seaside town, too-and genuinely excited about the potential of the structures we had put in place.

\section{Eco Action Network and Carbon Neutral 2030 Running into Problems}

Twenty months into our venture, things have panned out somewhat differently to what I expected in early 2020. COVID-19, like everywhere else, had a significant impact on Eastbourne's overall eco-activism and protest movements, on our Carbon Neutral 2030 campaign and on the Eco Action Network. We could no longer meet in person; projects had to be stalled; the Councils had to prioritise COVID-19 support (organising food aid and income support in particular); and, of course, COVID-19 also massively impacted our individual ability to keep this volunteer organisation running, due to the same range of challenging personal circumstances people throughout the world have been experiencingsickness, caring obligations, home-schooling, financial struggles, relationship breakdown. 
COVID-19 also brought to the fore underlying personality differences and tensions amongst the EAN directors. Shortly before the first lockdown in March 2020, our executive director Giles had suggested, and the rest of us agreed to, the appointment of three further directors, one of whom was Carl, the energetic leader of the Carbon Capture Group. Already then, differences were starting to emerge: whilst Carl and I were keen to get on with things - all, we felt, in the egalitarian, trusting and open spirit that was our agreed EAN approach —other directors were more concerned with correct procedures and drafting policies (in particular around health and safety, GDPR compliance and insurance). These differences-manifested also in greatly varying levels of formality in communication and presentation style - came to a head in late 2020, when, initiated by the five other directors, it was decided by majority vote that Carl and I should set up Treebourne and EcoEd2030 (the name of our Education Group by then) as independent CICs. Since then, the remaining EAN directors have continued to work with Eastbourne Borough Council on a number of different projects, but there has been only one EAN network-wide meeting, and Giles has recently had to temporarily step back for health reasons. As a network and an overall framework for linking Eastbourne's eco activists, experts, citizens and Council, working together in a coordinated way, the EAN is therefore largely dormant at the moment.

The Council, meanwhile, has had its own challenges; here, too, as mentioned above, existing financial problems and capacity limitations were greatly exacerbated by COVID-19. When I recently asked Catherine, the EBC Sustainability Officer, about the Council's 2030 action timetable, she laughed drily and told me:

"It's actually difficult to speak of a timetable or plan, looking forward, because we are not really in control. There is a great feeling of impotence. We struggle as much as the community groups. We are like a middle-man, all we can do is negotiate. The council is becoming, having to be, very reactive. Because we don't have the staff or resources to run anything ourselves."(reproduced from notes)

Formally, then, neither the Eco Action Network, with all its (we thought) well-designed structures for council-citizen collaboration, nor the Carbon Neutral 2030 campaign as a concrete, targeted, timetabled Council action plan, have really worked out so far. However, this does not mean it has been an all-round failure. In the following, I describe Eastbourne's current eco-action landscape as it actually is, before attempting an analysis of why some projects have worked out better than others.

\section{Eastbourne's Eco-Action Landscape Today}

Of the eight original EAN working groups, by far the most successful has been Treebourne. Carl managed to assemble a sizeable team of dedicated, skilled and experienced colleagues, including an ecologist and an excellent website designer; regularly rally dozens of tree planting volunteers at weekends; raise over GBP 430,000 through a Crowdfunder, matching Council funding and bids partnered with Trees for Cities and Urban Trees; build up key collaborations with nationwide partner organisations, in addition to local Council programmes and officers; and, most importantly, plant an impressive number of trees: so far 14,000 saplings-around a dozen different varieties and carefully sourced-have been planted in Eastbourne's Sevenoaks Recreation Ground and Tugwell Park. Councillor Richard, the EBC Climate Change Strategy lead, talked of Carl and Isabel (Carl's main co-leader) as a 'dream team', with whom 'everything had been going so much better than what he could possibly have hoped for'; Catherine, the Sustainability Officer, too, raved about how they just 'ran with it', that they were 'just fabulous. We really need that community leadership'.

The Transport Group has evolved somewhat differently. Led by Paul, a retired geologist, this group has also very actively engaged with the Council; for example, they studied the government's Decarbonisation and Transport Plan and produced a short summary for circulation amongst Councillors; they worked together with EBC to encourage East Sussex County Council (ESCC) to set up a Quality Bus Partnership; they produced 'Bus Back Better', a bus service improvement plant; and they are starting developing an Eastbourne- 
wide car-sharing scheme (delayed by COVID-19). James, a sixth-form student and the EAN's youngest member, was not only actively involved in the Stagecoach negotiations, he also led Eastbourne's 2020 and 2021 Car Free Day events, with street closures throughout Eastbourne. In this he was supported in particular by another Transport Group member, Victoria (more on Victoria later). There is thus perhaps a bit of a bifurcation in the Transport Group, with James and Victoria doing more visible, public-facing projects, whereas Paul and the Transport Group as a whole have focused more on research, lobbying, reports and consultations. Here, relations with both EBC and ESCC have sometimes been a little difficult, with frustrations on both sides; and even though quite few people bought bikes and took up cycling during lockdowns, Eastbourne is still a long way off from any real 'modal shift.'

EcoEd2030 has made some progress. We have developed a good core team, wider networks and partnerships within Eastbourne and across Sussex, and a social media presence. We send a monthly newsletter to schools and run themed termly online events, where different eco-providers present their offers; the first on tree planting was in June, a second one on energy in November 2021. In theory, this is what I had envisioned when setting up EcoEd2030: a platform that connects existing eco-providers with schools and supports and facilitates schools' 'eco-journeys'. I continue to believe that schools are crucial for meaningful local carbon emission reductions, both in terms of improving their own institutional carbon footprint, and in terms of catalysing green transition in the wider community; and that EcoEd2030 can support schools in this. However, in practice it has been very challenging. Our volunteer-run team is small and most work is done by very few (often just one) of us, and prone to people dropping out due to other commitment or illness. Building up actual collaboration with partners is challenging and time-consuming, and despite our efforts it remains extremely difficult to get real traction with schools.

In addition to these three original EAN working groups, there are other ongoing and new projects, some linked to or stemming from EAN, others independent. Suzy, for example, was initially part of the EAN Adaptation working group, but then started her own community garden and food project, the Blackberry Buzzers, as part of Grow Eastbourne; Grow Eastbourne in turn is linked to Edible Eastbourne and the Eastbourne Food Partnership. Bespoke Cycling (a group of dedicated town cyclists who have campaigned for better cycling infrastructure for 15 years) continue to meet, organise events and campaign; Clean Air Eastbourne, a successful local citizen-science project, installs Air Monitors in households and schools throughout the town and has raised awareness of Eastbourne's pollution problems; and Plastic Free Eastbourne is going strong, with hugely popular beach cleans, the Adopt a Beach programme and the launch of the Spring Water Festival (installing water fountains throughout Eastbourne). Eastbourne's climate protesters are also re-emerging: 500 or so people joined the COP26 Climate Justice March—organised by a group of long-term, dedicated activists from Eastbourne Greenpeace and XR, also connected to EAN social circles-on 6th November.

At the opposite end of the political spectrum are Rudolph, a hereditary member of the House of Lords, and his wife Victoria (already mentioned above), who moved from London to Eastbourne around 7 years ago, and are amongst its most prominent 'movers and shakers', to use one of Victoria's favourite phrases. Victoria has organised many different initiatives with Eastbourne schools, including school street closures, school walks, tulip planting and Birds2BeHeard, taking 5000 paper birds with messages from Eastbourne's school children to COP26. For two years in a row, she has brought 'Beat the Street', a programme that encourages people to walk through a tagging system, to Eastbourne, and she is very involved in the annual Eastbourne Walk Fest. Last year, Rudolph and Victoria also organised 'Making Natural History', a two-week-long online conference to mark the 25-year anniversary of the UN Children Climate Conference, held in Eastbourne in 1995. Their potentially largest project, still in its early stages, is to bring Eden to Eastbourne: Tim Smit, Rudolph and others are hoping to set up an Eastbourne-wide Eden, with different 
archaeological, wildlife and art sites across town and the Downs. The details of this are yet to be confirmed.

Eastbourne Borough Council itself, meanwhile, is currently working on a number of partnered projects. These include the Green Home Grant, an electric vehicle charging points scheme (together with Lewes District Council), and the Net Zero Innovation Programme, a university-council partnership project (https://www.local.gov.uk/together-towardsnet-zero-sandpits. (accessed on 17 October 2021)). This also presents a case study on alternative finance, raising money through a community bond, to help assist with better heating systems. Although this scheme itself is for municipal and council housing only, EBC and EAN together also recently held an online event on Eco Homes for Eastbourne residents, with advice on how to reduce a home's carbon footprint and energy bills (https: // content.govdelivery.com/accounts/UKEASTBOURNE/bulletins/2f659e2. (accessed on 17 October 2021)).

In short, more and more different green initiatives are emerging in Eastbourne, albeit not necessarily along the lines of what we initially envisioned in the EAN, and as yet no way near the rapid transition any form of 'Carbon Neutral 2030' would require. In the following, I think through why things have evolved the way they have, before reflecting on my own experiences and learning as an anthropologist, resident and climate activist.

\section{Thinking through Challenges and Successes}

At the heart of the limitations of Eastbourne's to-date somewhat tentative Carbon Neutral campaign lie the limited resources and powers of Eastbourne Borough Council. As already briefly mentioned above, our two-tier authority means that EBC is responsible for recycling, housing and some planning; ESCC for transport, education, and environment and planning throughout East Sussex. ESCC not only itself faces myriad, multiple pressures (most acutely around social care), it also has a strong conservative contingent amongst its Councillors. There are also various regional, political dynamics influencing what kind of infrastructure projects money is spent on, with the division of powers between EBC and ESCC in itself resulting in many ideas easily_-somewhat conveniently-falling between chairs. Where Council projects have succeeded, this has been due to successful partnerships and projects that can be outsourced and are politically and structurally relatively easy to deliver, in addition to particularly energetic and committed individuals. This is, of course, why Councillors were so keen to help establish and work with the Eco Action Network, but the limited quantity of resources available and heavy reliance on volunteer labour is challenging for all involved. Altogether, a number of different factors have played a role in shaping the current contours of Eastbourne's eco-action landscape as a whole: (a) different understandings of council-citizenship collaboration; (b) institutional and political barriers; (c) the 'feelgood fallacy'; (d) the 'who' of Eastbourne eco-action; and (e) personal characteristics and interpersonal relations.

(a) Council-citizenship collaboration-different understandings. Despite all our shared initial optimism and excitement over the EAN collaborating with Council to honour the Carbon Neutral 2030 commitment, there were some fundamental differences in understanding about what council-citizen collaboration entails. Giles, Henry and other EAN members thought of the EAN primarily as a pressure group and of themselves as advisers and lobbyists. They felt their main role was to put pressure on Council to deliver the infrastructure and wider changes needed for Eastbourne to become carbon neutral. However, EBC Councillors and officers, who represent a Town Council run on a shoe string and with very limited capacities, were keen to set up and support EAN as almost an extension organisation for EBC, which would raise the funds and do the actual delivery of carbon neutral projects. This understanding is, of course, informed and part of a wider trend towards public-private partnerships of this kind, in addition to, perhaps, a legacy of David Cameron's 'Big Society'.

It is no wonder that, for EBC councillors, Treebourne is the 'dream team', doing exactly this: raising funds and mobilising large amounts of community labour, with 
Council providing land and support from Council officers. Treebourne is, in a very real sense, an extension of, and doing work for, the Council. At EcoEd2030, too, I do very similar work to Sustainable Education Officers employed by better resourced City Councils, such as Brighton and Hove, Leeds or Leicester. Giles and Henry, however, do not want to play this role; they, very rightly, resent being asked to deliver Council work for free. To some extent, we were all aware of and accepted that both conceptions of council-citizen collaboration were legitimate and part of what EAN is about; in practice, however, it has meant that delivery projects such as Treebourne, and personal relations between its leaders and Councillors and Council officers, thrive, whereas those groups that see themselves more as lobbyists and advisors, such as Transport and, in particular, the EAN leadership, have struggled more, and relations with Council(s) are sometimes more difficult.

(b) Institutional and political barriers. The main activities involved in our two biggest success stories at the moment, Treebourne and Plastic Free Eastbourne-tree planting and picking up litter — can quite easily be carried out by volunteers and citizens, whereas a large part of the measures required to reduce transport carbon emissions are fundamentally more about infrastructure changes that indeed need to be delivered by the authorities-better public transport provisions, more extensive and safer cycling and walking infrastructure, etc. This means that putting pressure on Council to do something really is the main strategy available here. The particular problem with transport and cycling infrastructure is that it is under the remit of Conservative-dominated ESCC, for whom sustainable transport is not a priority-there is no Ann Hidalgo here yet. On the contrary, influential lobbying groups in the background seem very adept at systematically ensuring that every public consultation results in the scrapping of proposed cycling infrastructure improvements; in addition, ESCC has limited resources and many other obligations. As a result, Eastbourne remains straddled with an appallingly bad cycling infrastructure, despite years of campaigning by Bespoke Cycling and the Transport Group.

At EcoEd2030, we have had similar experiences and difficulties dealing with schools. Like Councils, schools are under-funded, under-staffed and over-worked, and also have to constantly balance a whole range of pressing demands on time, attention and resources. Like local councils, schools are also subject to the ever-changing caprices of government regulations, funding cuts and targets, which greatly curtail their freedom and liberty to act quickly. In general, we are learning that both schools and councils, as institutions, have their own procedures, habits and ways of thinking that are difficult to understand and penetrate as outsiders.

(c) The 'feel-good fallacy'. Admirable and important as they are, arguably tree planting and beach cleans are both 'soft' forms of environmental action, palatable to both Conservative councils and to citizens. They are 'add-on' activities that make those involved feel good and that we are doing 'something', but they do not require fundamental change from anyone, allowing everything else to continue as before-the 'feel-good fallacy', as Rebecca Willis [9] calls it, one of many different forms of climate delay [10]. It is when it comes to real changes in lifestyle, infrastructure and thinking - the kinds that really are required to achieve carbon neutrality by 2030 and, indeed, any chance of staying below 1.5 or even $2{ }^{\circ} \mathrm{C}$ warming - that you run into difficulties. This applies, perhaps, particularly to car dependency. Current developments in Eastbourne are, in fact, in the wrong direction, with more cars (including significantly more SUVs) on the roads and more miles driven every decade [11]. Eastbourne is far from alone in this; globally, emissions from transport are rising more than from any other sector, and it is overall one of the most difficult sectors to tackle [12].

(d) The 'who' of Eastbourne eco-action: age and class. The reliance on unpaid, volunteer labour throughout Eastbourne's eco activities not only makes all these projects inherently fragile and subject to abrupt changes and endings due to changing personal circumstances, it also means that it is more difficult to put in the necessary time for those who have to work for a living and with caring responsibilities, and slightly easier for the retired and well-off. This in itself, although not necessarily and not always, can create a certain bias 
towards projects with more cautious understandings of environmental action. Plastic Free Eastbourne, for example, is, in part, such a success because it is run by a retiree with comparatively few household, work and childcare commitments. Its leader, Alexander, works incredibly hard and puts in many, many hours of work, but beach cleans and the installation of water refill stations are both relatively small steps as eco-actions (as, to be fair, Alexander readily acknowledges).

Formal high status, too, brings more power and leverage. As Lord and Lady, many people in provincial Eastbourne subconsciously or consciously listen to and are more willing to work with Rudolph and Victoria than others. They are able to draw on their wider connections and social capital to bring in outside partners such as Beat the Street or the Eden Project. All this means that more conservative, established projects are overall better resourced, and have more support and people behind them, than more radical ideas and projects.

(e) Personal characteristics and interpersonal relations. Having said this, Suzy, Carl and others have achieved amazing things despite formidable work and childcare challenges and without previous 'connections', because they are driven, good at getting things done and can work with many different kinds of people. In the successes of Victoria, Rudolph and Alexander, determination and energy, in addition to, of course, concern over environmental issues and civic-mindedness, are also crucial-after all, there are countless well-off, wellconnected retirees who would never dream of becoming involved in eco- action. Conversely, bureaucratic outlook and preoccupation with procedure and policy amongst some of the remaining EAN directors may, arguably, have played a role in hampering its development.

In general, like voluntary initiatives everywhere, Eastbourne's activist and volunteering 'scene' has its fair share of personality clashes and interpersonal conflicts. This is an inevitable consequence of a somewhat random collection of people, with very different outlooks, backgrounds, levels of education and motivations, trying to work together. There are also more emotions and less restraints than in paid work-people care very much about the issues, but do not have to worry about losing a job and income. In addition, the time demands of activism and volunteering can create considerable extra stress and negatively affect people's mental wellbeing, occasionally making arguments more acrimonious and heated than they would otherwise be.

\section{Reflections on Activist Anthropology 'at Home'}

"reflection-true reflection-leads to action. On the other hand, when the situation calls for action, that action will constitute an authentic praxis only if its consequences become the object of critical reflection" Paulo Freire, Pedagogy of the Oppressed" [13]

It was in February 2019, whilst watching a short clip of one of the first youth marches and listening to their young voices demand change, that I had what others have aptly called an 'ecophany' (this term comes from the Financial Times, 11 April 2019, 'Extinction Rebellion: inside the new climate resistance', https://www.ft.com/content/9bcb1bf8-5b2 0-11e9-9dde-7aedca0a081a. (accessed on 18 October 2021)): the realisation that, as a parent and adult, I had to start acting about climate change RIGHT NOW. Not just reading and worrying, but really doing something. There and then, I set up a WhatsApp group for fellow school parents who I thought might also be interested in setting up a 'Parents for Climate' group, and began linking up both with other parent groups around the UK and globally (joining the 'Parents for Future' network). Later, this group became Eco Action Families, which I still run as a WhatsApp group for eco-minded parents/friends, but over time I focused more on EAN and then EcoEd2030. Overall, eco-action has become a significant, all-consuming part of my life: meetings, emails, social media posts, website updates; funding applications, stall events, talks and presentations; litter picks, recycling, tree planting, school street closures, cycle rallies, marches, protest actions; and, basically, non-stop reading, thinking, learning, connecting. 
The personal costs of all this have been high: the many thousands of hours of work (much of which both mundane and fruitless) and the stresses, frustrations and difficult personal relations involved, have taking their toll on my current research project and academic progress, on my children, marriage, friendships, and, of course, myself. These personal struggles are hard to bear, seem ridiculous even, when you know that in other parts of the country this job is essentially a paid Council position; and especially when, again and again, the results are so pitiful in proportion to the effort going in. Just in the last few weeks, I spent many working hours trying to get schools to enrol in our latest EcoEd2030 Info \& Connect event, but in the end only around a dozen schools attended, and it may not have resulted in any take-up at all. There have been many times when I have been very close to complete burnout and to resigning; to date, I have always pulled back and continued, but am feeling the burden (and futility) of it all more and more.

Nevertheless, it has also been enormously beneficial and rewarding; I have learned and gained so much personally, as an anthropologist and as an activist. In fact, the intertwining of the personal, activist and anthropological has been part of the learning processes and mutual enrichment. My key areas of 'learning' have been around (a) place and community; (b) people and personalities; (c) intermediate climate governance and institutions; (d) labour and money; and (e) power. Some of these overlap with the analysis of Eastbourne successes and failures in the previous section, but I discuss them now from a more 'general learning' angle:

(a) Place and community. For a start, I have deeply connected with Eastbourne as a place and as community. We moved here in 2014, and commuting to London and full-time work meant that I only very gradually and minimally learned my way around town and only met neighbours and fellow nursery and school parents. Now, through my involvement in eco-activism, only possible because of being on research leave, I know Eastbourne and its history and surroundings so much better, and I know many different people, including activists, organisers, councillors, council officers, artists, musicians, and MPs. This growing 'social capital' - knowledge of and connection to 'Who is Who' of Eastbourne-is essential for trying to advance our goals with EcoEd2030, but it's also personally enriching to truly connect to the place where you live as a citizen, and indeed very interesting as an anthropologist to gain insights into a provincial Sussex town-community, politics, networks and all.

(b) People and Personalities. I am learning to recognise, respect and work with different qualities, strengths and weaknesses in others and myself, and to identify different 'types' - bureaucrats, researchers, campaigners, doers; or crusaders, entrepreneurs, pragmatists and weavers, i.e., the key 'types' Yuille, Tyfield and Willis identified [7]. Most importantly, I am learning and thinking about the limits to our capacity to fully engage with climate change. Lively and impressive as our Eastbourne eco-action scene is, it is also very small-always the same three dozen or so people doing everything. In the town as a whole, we have some very active resistance (e.g., 'Afoot', led by a BNP member, has successfully campaigned against new cycle paths for the past decade); our fair share of climate-denial scorn and scepticism, sometimes very evident in the local Facebook group 'Eastbournians'; and, above all, a large majority of people who are not climate change deniers, as such, but who do not really engage with anything much beyond their family, friends and work. I am not talking here about Eastbourne's many disadvantaged and struggling families (some Eastbourne wards are among the country's 20\% most deprived; see https: / / www.eastbourneherald.co.uk/news / deprivation-eastbourne-third-highestsussex-1181740. (accessed 18 October 2021)), but those I encounter every day in my relatively affluent neighbourhood and at school. Many are friendly, perfectly nice people who do many good things and are generally supportive of what we do, but most are not in panic mode about climate change and do not feel they need to become climate activists themselves. Sometimes, I despair a little at 'school mums', who seem to spend so much time supporting their children at school, driving them to after-school activities (SUVs increasingly the family car of choice), walking their dogs, doing sports, and who seem to 
think and talk only about these things (I acknowledge this is an unfair description-the reality always far more complex, I know). Experiencing this, as I do, every day, I think more and more about how our whole education system and culture are currently geared towards recreating inward-looking nuclear families, obedient, skilled workers and consumers-an overall culture of 'un-care', as Sally Weintrobe calls it [14]—not towards critical, complex thinking, activism, community or care.

(c) Intermediate climate governance and institutions. We all used to have heated 'government action vs. individual lifestyle changes' debates, but it is now increasingly recognised that both are necessary for addressing the climate emergency. Somewhat less attention is paid, however, to intermediate levels of governance and action, namely, local governments and institutions such as schools, even though-as law-makers, law-enforcers, 'nudgers' and (re)creators of culture, values and infrastructure - they are crucial for linking government directives and individual lifestyle changes, and for bringing about the local infrastructure changes, modal shifts and transitions we require. Over the course of my involvement here in Eastbourne, I have become only more convinced of their importance, and continue to strongly advocate a focus on and targeted mobilisation of such intermediate levels of governance. However, I have also learned just how difficult local councils and schools are to approach, change and 'win over' for outsiders and from below. Both are institutions with procedures, rhythms, organisational hierarchies and 'key people' that you need to learn your way around, and both are under-resourced, straddling many responsibilities simultaneously, and subject to vast amounts of government pressure and regulation. In Eastbourne, moreover, both local government and the majority of schools are currently very much bastions of, and embedded in, Eastbourne's overall conservative, small-town culture. A visionary, committed Head can make a massive difference-this has been very much the case for the two schools in the area that have long been pioneers in eco-changes (there are interesting parallels here with Sustainability Officers in the palm oil industry highlighting the importance of a CEO's personal commitment to sustainability [6]). The Heads of many other Eastbourne schools, however, like the majority of Eastbourne residents, are personally, it seems, not interested in climate change. Ultimately, we need government legislation and funding to make it both obligatory and feasible for all schools to change. As hard as we try, our volunteer-led, unfunded 'badgering' from below can only have limited effects. This applies not just to schools, but to our whole local 'carbon neutral' initiative: not only is it impossible, really, to achieve local carbon neutrality in isolation from wider national/global changes, it is also very difficult to make any changes at local level without adequate funding and guidance from national government. The real power and importance of both local governments and schools ultimately may lie less in (so exhausting yet so pitiful) local initiatives like ours, but in being key instruments of delivery of wider, national initiatives.

(d) Labour and money. Feeling this so keenly myself, I have been thinking a lot about the labour involved in climate action. Organising protests; nudging, lobbying, campaigning; planting trees, insulation and retro-fitting; building cycle lanes or flood protection-it all requires many, many hours of work by many different people throughout the world. At the moment, however, there is often a significant 'misfit' between where and by whom the real, most-needed work is done, and where money flows. So much crucial frontline work, whether protesting against a new plantation or mine, or planting trees, often involves huge sacrifices and risks, especially by those in the Global South (the real frontline, not Eastbourne), yet is entirely unpaid and unrewarded. There is plenty of money, however, in the rapidly growing corporate 'sustainability drive' [6], a much softer form of environmentalism, if not outright 'greenwash'. Money and class, as discussed above, also shape charities, CICs and volunteering, again often favouring more conservative, softer, business-oriented environmental ideas and practices. All this is increasingly recognised, and there are a number of proposals and initiatives that can potentially help to combat this labour/money 'misfit', by either creating paid jobs where they are really needed or by enabling far more of us to do 'free', voluntary labour-Green New Deals, Crowdfunding, Universal Credit, and 
4-Day weeks - and activist academics are advocating activism, community or climate work to become as accepted as consultancy work. We have a long way to go, but the beginnings are there.

(e) Power. As a social scientist, I have long been teaching and writing about power, drawing on the works of Gramsci, Foucault and Lukes, amongst others [15-17]. However, becoming part of a movement and leading an organisation with a particular goal has taught me so much more about power: both the embodied, acute sense of disempowerment our struggles and failures here in Eastbourne have generated, and my growing awareness of the global climate movement and the formidable challenges and resistance it is encountering. Overall, I have found Gramsci's [15] concepts of hegemony and counter-hegemony the most useful: for understanding how elite interests, politics, capital, media, security forces and culture co-create and entrench climate 'delayism' and 'business as usual', but also for thinking through the tools we have for challenging this hegemony, changing 'common sense' within civil society and creating an alternative counter-hegemony. For a while this morphed, in my angry brain, into a somewhat simplistic 'us and against them' thinking (useful too!). However, I am currently moving back towards a more nuanced understanding that is closer, in fact, to Gramsci's ideas, in that, of course, 'we' are not outside but all part of and within the current system, as employees, employers, citizens, consumers, parents, teachers and students, in addition to activists, where we each inhabit our own unique positions of power and leverage, and can make a difference. This, indeed, feeds into my 'theory of change', which I end this paper with, by way of a conclusion.

\section{Conclusions (a 'Theory of Change' of Sorts)}

This paper describes, from the vantage point of an active participant, our experiences in Eastbourne with local council-citizen collaboration on carbon neutrality. It discusses why, after a promising start in 2019, overall progress has been slow, and why some projects have been more successful than others-showing how limited resources, institutional, class and power dynamics, the inherent weaknesses of volunteering, Eastbourne's conservatism and the 'feel-good fallacy' have all played their part. The paper includes a discussion of Eastbourne's wider eco-landscape beyond the specific Carbon Neutral commitment and the Eco Action Network, showing simultaneously that the many different ongoing and newly starting groups and initiatives are symptomatic of wider, positive change, but also that do not yet add up to meaningful carbon reduction. The paper also describes my own subjective experiences, thoughts and emotions, as an anthropologist and working mother embarking on local activism. The personal costs have been so high that I have very often been very close to 'burnout', but it has also been, and continues to be, enriching in many different ways.

Overall, much of this paper describes the real limits of what can be done bottom-up at local level and by volunteers, and points to the urgent need for national strategies and funding that recognise the importance of local governments in delivering the infrastructural and cultural changes we so urgently need to make. This is certainly a key lesson that I am learning here in Eastbourne. But it is not the only one. For one, yet another call for government funding and intervention-persuasive as it may be-is not enough at this stage. We do urgently need proper government funding in local governments to address the climate emergency, but we also need so much else. Indeed, limited, unsuccessful and difficult as our efforts have so far been here in Eastbourne, they are beginning to make small differences, and point, for me, towards a more holistic (perhaps idealistic) way forward than just better government policy, so slow to materialise. For what it is worth, then, I conclude this piece by sharing my own 'theory of change' such as it has emerged over the last two years. I am inspired in this by the activist Sydney Azari, who just yesterday asked us to 'normalize having a theory of change' (https: / twitter.com/SydneyAzari/status / 1464850685929820162?s=20. (accessed 28 November 2021)). It has three facets that are all interlinked, but I have written them out separately as each has a slightly different emphasis and engages with different debates. 
(a) Radical Pragmatism. Larger debates in the climate movement, around whether we need to dismantle the current system/capitalism or work within it, also play out at the local level: who do you work with, what projects do you get into? I believe in eco-socialism and degrowth, and I am a strong supporter of climate protests and marches, which, post COP26, we need more than ever. However, I also recognise the importance and possibilities of working within the system, and the immense amount of - detailed, frustrating, difficultwork being done here by so many 'pragmatists' (see also [9]). Noam Chomsky recently stated that, as much as we would like to, it would be impossible to change the whole system and dismantle capitalism within the little time we have to tackle the climate emergency (https:/ / www.vox.com/energy-and-environment/21446383/noam-chomskyrobert-pollin-climate-change-book-green-new-deal. (accessed 18 October 2021)). Similarly, at local level, in order to get more leverage, I have opted for a pragmatic approach and collaborate with almost everyone, including those with very different politics and more conservative understandings of and approaches to environmental action. I am acutely aware that this approach has real costs-it is stressful and often frustrating, and there is an ever-present danger of compromising your own beliefs, and indeed contributing to saving the 'status quo'. (Indeed, the moral dilemmas around these choices have been a theme in three otherwise very different papers I wrote this year, about Sustainability Officers in the corporate palm oil sector, my own involvement in 'rescuing' Okomu National Park in Nigeria, and the current paper $[6,18]$.) However, I believe that, in the little time we have, we need everything, everywhere, all at once, continuously: protests, petitions, marches, boycotts, movements, direct action, hunger strikes, personal lifestyle changes, targeted lobbying, committed politicians, academics working with politicians and yes, even corporations.

(b) Organic Change and Social Networks. Targets, planning and measured data play a central role in climate action, for many good reasons-not least because we do ultimately need strong government-led action, and that is how governments work [19]. However, net zero targets can be very problematic, in that they legitimise and encourage a 'last-minute' approach and reliance on as-yet un-invented carbon capture technologies [20]. Moreover, our local experience here in Eastbourne has shown that 'carbon neutrality' is hard to define, measure and achieve at the local level, and that planning can be hugely difficult. As described throughout this piece, our ideas for organising and bringing about eco-action have only partly panned out the way we, the founders of the EAN, envisioned. However, like a stone thrown in water creating ripples that you may never see the full extent of (this image and idea came from this tweet: https:/ / twitter.com/rwclimate/status/1442452573 949210628?s=20. (accessed on 19 October 2021)), I am learning to appreciate that there ARE many different small, unseen, unmeasurable impacts resulting from our activities: families and schools make their own changes and start projects that you never hear about; and new, unplanned connections, projects and ideas emerge from and between participants. Our obsession with targets and measurability means we can easily miss all these lesstangible effects. Even with the awfully real deadlines set by irreversible climate change, I would advocate open-mindedness and flexibility - try a strategy you believe in, but also be open and appreciate unanticipated, unmeasurable outcomes, adapt and embrace new, unexpected possibilities, and value unplanned, organic change stemming from unplanned, organic social relations.

(c) Murmurations: Collective, Situated Power. In the face of the enormity of the challenge ahead, in addition to entrenched, powerful interests actively preventing real change, it is easy to feel completely disempowered and overwhelmed, and to think that there is nothing you can do as an individual. However, this is not true. As discussed above, we all, each of us, occupy particular positions within the overall system, as workers, citizens, and social beings. We are nurses, factory workers, civil servants, business owners, artists, poets, engineers, teachers; school governors, church and sports club members; cousins, children, parents, friends. As such, we each have skills and powers that we can utilise to help. A single action - a poem, a new cycle rack here, a letter to an MP there-may not feel like 
much, but collectively—-like birds' murmurations, to use Andy Stirling's [21] evocative term that brilliantly captures this-it all adds up. Importantly, nobody needs to stretch themselves: everyone just needs to do what they are good at, like, and can do easily, and it all contributes. All the more so because each of our powers and social networks are unique to us-my reach, my skills, are different to yours. It is collectively that our reach becomes big.

To bring all three strands together: in my hopeful moments I see potential in the spontaneous, organic activation, 'switching on' one after the other, of more and more people, like a chain of beacons. This is not instead of government action; on the contrary, both are necessary and indeed interlinked and mutually supportive. Of course, it is not easy to 'switch on' people; most of my efforts with fellow school mums, neighbours, schools, etc., have so far failed miserably. But we must keep on trying in every way we can, for each single new person you do manage to reach—each having their own 'ecophany' and utilising all the powers they have-can contribute to changes in households, schools, clubs, communities and businesses, and in local, national and global governance. In fact, much of this, as I have tried to show, is happening already at a small local scale here in Eastbourne and in countless different ways throughout the world, and it may just all gather momentum in the right directions more quickly than we can anticipate now.

Funding: This research received no external funding.

Informed Consent Statement: Informed consent was gained from Eastbourne Borough Council and all key participants.

Acknowledgments: I would like to thank the Leverhulme Trust for affording me the time to complete this work. I am also grateful for the positive support from EBC councillors with whom I discussed writing this article, to David Tyfield and Rebecca Willis for inviting me to submit a paper to this Special Issue, and to my anonymous reviewers for constructive feedback. Finally, I would like to thank the Twitter climate action community, which has inspired and informed me so much in doing this work.

Conflicts of Interest: The author declare no conflict of interest.

\section{References}

1. Green, J. Less Talk, More Walk: Why Climate Change Demands Activism in the Academy. Daedalus 2020, 149, 151-162. [CrossRef]

2. Power, A. The Future of Academic Activism? Available online: https://www.torch.ox.ac.uk/article/the-future-of-academicactivism-0 (accessed on 17 October 2021).

3. Gardner, C.J.; Thierry, A.; Rowlandson, W.; Steinberger, J.K. From Publications to Public Actions: The Role of Universities in Facilitating Academic Advocacy and Activism in the Climate and Ecological Emergency. Front. Sustain. 2021, 2, 42. [CrossRef]

4. von Hellermann, P. Things Fall Apart? Forest Governance in Southern Nigeria; Berghahn: New York, NY, USA, 2013.

5. von Hellermann, P. Tree Symbolism Old and New in the Pare Mountains, Tanzania. Conserv. Soc. 2017, 14, 368-379. [CrossRef]

6. Delabre, I.; von Hellermann, P. Selling out for Sustainability? Neoliberal governance, agency and professional careers in the sustainable palm oil sector. J. Political Ecol. 2022. (submitted).

7. Yuille, A.; Tyfield, D.; Willis, R. Implementing Rapid Climate Action: Learning from the "Practical Wisdom" of Local DecisionMakers. Sustainability 2021, 13, 5687. [CrossRef]

8. Eastbourne Carbon Neutral 2030. Baseline Report and Action Plan November 2020. Eastbourne Borough Council. Available online: https:/ / democracy.lewes-eastbourne.gov.uk/documents/s18246/Eastbourne\%20Carbon\%20Neutral\%202030\%20A\% 20plan\%20for\%20action\%20-\%20Appendix\%201.pdf (accessed on 18 October 2021).

9. Willis, R. Too Hot to Handle? In The Democratic Challenge of Climate Change; Bristol University Press: Bristol, UK, 2020.

10. Lamb, W.F.; Mattioli, G.; Levi, S.; Roberts, J.T.; Capstick, S.; Creutzig, F.; Minx, J.C.; Müller-Hansen, F.; Culhane, T.; Steinberger, J.K. Discourses of climate delay. Glob. Sustain. 2020, 3, E17. [CrossRef]

11. Eastbourne's Direction of Travel: Issues and Options for the Eastbourne Local Plan. Planning Policy, Eastbourne Borough Council, November 2019. Available online: https:/ / planningpolicyconsult.lewes-eastbourne.gov.uk/gf2.ti/-/1076866/58269221 .1/PDF/-/Eastbournes_Direction_of_Travel_Issues_and_Options_for_the_Eastbourne_Local_Plan_FINAL.pdf (accessed on 14 December 2021).

12. Mattioli, G.; Roberts, C.; Steinberger, J.K.; Brown, A. The political economy of car dependence: A systems of provision approach. Energy Res. Soc. Sci. 2020, 66, 101486. [CrossRef]

13. Freire, P. Pedagogy of the Oppressed; Penguin Books: London, UK, 1993. 
14. Weintrobe, S. Psychological Roots of the Climate Crisis. Neoliberal Exceptionalism and the Culture of Uncare; Bloomsbury: London, UK, 2021.

15. Gramsci, A. Selections from the Prison Notebooks; Hoare, Q., Smith, G.N., Eds.; Lawrence \& Wishart: London, UK, 1971.

16. Foucault, M. Power/Knowledge: Selected Interviews and Other Writings 1972-1977; Harvester Wheatsheaf: Hemel Hempstead, UK, 1980.

17. Lukes, S. Power: A Radical View, 2nd ed.; Palgrave Macmillan: Basingstoke, UK, 2005.

18. von Hellermann, P. Being the (Neoliberal) Conservationist: An anthropologist's entanglement in 'rescuing' Okomu National Park. In Proceedings of the RAI Conference Anthropology and Conservation, London, UK, 25-29 October 2021.

19. Scott, J. Seeing Like a State. How Certain Schemes to Improve the Human Condition Have Failed; Yale University Press: New Haven, CT, USA, 1999.

20. Dyke, J.; Watson, R.; Knorr, W. Climate Scientists: The Concept of Net Zero is a Dangerous Trap. In The Conversation, 22 nd ed.; 2021. Available online: https:/ / theconversation.com/climate-scientists-concept-of-net-zero-is-a-dangerous-trap-157368 (accessed on 16 October 2021).

21. Stirling, A. How Deep is Incumbency? Introducing a 'Configuring Fields' Approach to the Distribution and Orientation of Power in Socio-Material Change. Available online: https://steps-centre.org/publication/how-deep-is-incumbencyintroducing-a-configuring-fields-approach-to-the-distribution-and-orientation-of-power-in-socio-material-change/ (accessed on 17 October 2021). 